\title{
The effect of a split portion of flaxseed on 24-h blood glucose response
}

\author{
Awatif Almehmadi $^{1,2} \cdot$ Helen Lightowler ${ }^{1} \cdot$ Magali Chohan $^{3} \cdot$ Miriam E. Clegg $^{4}$
}

Received: 15 October 2019 / Accepted: 7 July 2020/ Published online: 22 July 2020

(c) The Author(s) 2020

\begin{abstract}
Purpose Flaxseed can be effective at lowering and stabilising blood glucose responses. The aim of this study was to determine whether flaxseed could lower blood glucose response more effectively when consumed as a single portion of $30 \mathrm{~g}$, or a split portion consumed three times per day ( $10 \mathrm{~g}$ flaxseed per portion).

Methods The study was a randomised, repeated measures, cross-over design. Fifteen healthy participants consumed either (1) three flaxseed muffins containing a total of $30 \mathrm{~g}$ of flaxseed once in the morning, (2) three flaxseed muffins consumed at three different timepoints across the day (10 g flaxseed per muffin) or (3) three control muffins consumed at three different timepoints across the day ( $0 \mathrm{~g}$ flaxseed). The 24 -h blood glucose response was measured using a continuous glucose monitor. Results The results of this study demonstrated that flaxseed muffins given three times a day were effective at lowering and maintaining blood glucose levels over $24 \mathrm{~h}$, compared to the control muffins and that both flaxseed treatments resulting in a lower blood glucose iAUC during the night.

Conclusion The results of this study indicated that adding flaxseed to a daily diet produced a lower glucose profile over $24 \mathrm{~h}$ in a free-living context compared to the control muffins.
\end{abstract}

Keywords Flaxseed $\cdot$ Linseed $\cdot$ Blood glucose $\cdot$ Continuous glucose monitor $\cdot$ Blood glucose incremental area under the curve (iAUC) $\cdot 24$ blood glucose profile

\section{Introduction}

There is a considerable body of evidence indicating that the consumption of low glycemic index (GI) foods reduces blood glucose fluctuations, and benefits the management and

Miriam E. Clegg

m.e.clegg@ reading.ac.uk

Awatif Almehmadi

amsmehmadi@uqu.edu.sa

1 Department of Sport, Health Sciences and Social Work, Faculty of Health and Life Sciences, Oxford Brookes University, Oxford OX3 OBP, UK

2 Department of Clinical Nutrition, College of Applied Medical Sciences, Umm Al-Qura University, 21421, Makkah, Saudi Arabia

3 Department of Health and Exercise Science, Faculty of Sport, Health and Applied Science, St Mary's University, Twickenham TW1 4SX, UK

4 Department of Food and Nutritional Sciences, School of Chemistry, Food and Pharmacy, University of Reading, Reading RG6 6AP, UK prevention of diabetes and prediabetes [1-3]. Low GI foods help to stabilise blood responses at a normal level for longer period of time [4] minimising potentially large fluctuations in blood glucose levels [2, 5]. Epidemiological evidence suggests that postprandial blood glucose levels are more strongly related to cardiovascular events than fasting blood glucose in individuals with diabetes $[6,7]$. Current eating patterns can mean that a high proportion of the day is spent in the postprandial state, which produces the highest plasma glucose levels [8].

Foods which contain a high amount of fibre generally have a lower postprandial blood glucose and insulin response, a lower GI, and are more effective at preventing type two diabetes in healthy individuals [1]. Flaxseed is considered to be one of the key plant sources of dietary fibre, as it contains both soluble and insoluble fibre with a ratio of soluble to insoluble varying between 20:80 and 40:60. The soluble fibre in flaxseed is mucilage gum and insoluble fibre is cellulose, hemicellulose and lignin $[9,10]$.

Previous studies have demonstrated that flaxseed can be effective at lowering and stabilising the blood glucose response in healthy, pre-diabetic and diabetic individuals 
[11-15]. The question remains as to whether flaxseed is more effective at maintaining blood glucose at the normal level over $24 \mathrm{~h}$ when the portion is given once or spread out throughout the day. The majority of studies on flaxseed and glycaemic response gathered the data in a laboratory setting the morning after an overnight fast, which does not represent the physiological responses across a full day.

Continuous glucose monitoring systems (CGMS) provide a method of evaluating subcutaneous interstitial fluid glucose over a number of days, by applying an electrochemical detector under free-living conditions [16]. CGMS evaluates interstitial glucose concentrations every $5 \mathrm{~min}$ and are minimally invasive, which gives an opportunity to evaluate the direction, magnitude, duration, frequency and causes of fluctuations in blood glucose levels [16, 17]. It can give a detailed view of the blood glucose profile, which can potentially show when and to what extent, an intervention affects the glycaemic response, while allowing the participants to continue their daily lives and activities uninterrupted [5, 18].

Currently, to best of our knowledge, no study has investigated the effect of splitting a portion of flaxseed on blood glucose control, or whether the flaxseed is more effective administered in a single or split portion. In the current study, the flaxseed portion was split over the three meals, which may cause a lower blood glucose post each of the three meals. The aim of this study, therefore, was to determine the most effective timing of flaxseed consumption to lower blood glucose response in healthy participants. This study used a single and a split portion regimen and investigated the blood glucose response over a 24-h period using a CGMS to determine whether flaxseed was more effective when consumed as a single portion of $30 \mathrm{~g}$ or as a split portion consumed three times per day (10 $\mathrm{g}$ flaxseed per portion).

\section{Materials and methods}

\section{Participants}

Healthy male and female adults aged between 18-60 years were recruited into this study at Oxford Brookes University through advertisements containing the researcher contact details between March 2017 and November 2017. The inclusion criteria were; aged 18-65 years; Body mass index $(\mathrm{BMI}) \leq 30 \mathrm{~kg} / \mathrm{m}^{2}$; fasting blood glucose $<6.1 \mathrm{mmol} / \mathrm{l}$; notpregnant or lactating; no known diabetes or impaired glucose tolerance; no medical condition(s) or medication(s) known to affect glucose regulation or appetite and/or which influence digestion and absorption of nutrients; no major medical or surgical event requiring hospitalisation within the preceding three months; and no food allergy or intolerance to any of the study foods. Ethical approval for the study has been obtained from the University Research Ethics
Committee at Oxford Brookes University (UREC Registration No: 161046).

\section{Study design}

The study was a randomised, cross-over repeated measures design. Participants undertook seven visits in total, the first was the screening visit, three initial sessions for sensor insertion and three follow-up sessions for sensor removal.

\section{Consent and screening}

During the screening visit, participants were asked to sign a consent form and to complete a health questionnaire, which included questions regarding to food allergies/intolerances, metabolic diseases, smoking habits, physical activity, medical conditions and medication. After completing the questionnaire, the following anthropometric measurements were taken: height using a free-standing stadiometer (SECA, Germany), body weight, body fat percent and fat-free mass using the Tanita body composition analyser (BC-418, Tanita UK Ltd, Middlesex, UK). Height was recorded to the nearest $0.1 \mathrm{~cm}$ and body weight was recorded to the nearest $0.1 \mathrm{~kg}$. If the participants were eligible after taking the anthropometric measurements and did not have any of the exclusion criteria, then a fasting (overnight for $12 \mathrm{~h}$ ) blood glucose measurement was taken from a finger-prick blood sample to determine the baseline data for glucose and if the participant was eligible to participate in the study.

\section{Test days}

At the initial sessions the CGMS sensor was inserted under the skin in the abdominal region between $15.00-17.00 \mathrm{~h}$ the day before the test day. Participants collected food for the test day, as well as prepared food for an evening meal the day before the test day. This ensured all participants began the test day following a similar meal. There was no need to fast for the sensor insertion session and there were no restrictions on the types of clothes that could be worn.

Participants were required to remain at the Oxford Brookes Centre for Nutrition and Health for $1 \mathrm{~h}$ to allow the sensor to initialise after trained personnel inserted the sensor. The participants were required to take four capillary finger-prick blood glucose readings using a single use lancing system (Unistik 3, Owen Munford, Woodstock, UK). The readings needed to be taken one and $2 \mathrm{~h}$ after the insertion of the sensor, before dinner and before bedtime. The purpose of the capillary finger-pricks was to calibrate the CGMS sensor.

All participants were provided with a finger-prick blood glucose monitoring device (ACCU-CHEK ${ }^{\circledR}$ Performa Nano, Roche Diabetes Care Limited, Burgess Hill UK). 
Participants were provided with written instructions on using the device and performing a capillary finger-prick; all participants were also trained to carry on taking blood glucose readings by themselves while the sensor was inserted, participants were required to avoid alcohol and restrict intense physical activity (e.g., long periods at the gym, running, aerobics). Dinner on pre-test day needed to be consumed between 18.00 and $20.00 \mathrm{~h}$.

On the test day which came the day after sensor insertion, the participants were required to take four capillary finger-pricks to measure blood glucose readings following the same procedure as the day prior the test day (before each main meal and before bedtime). Participants were aware of how to follow the correct procedures to dispose of the waste safely and they were provided with a clinical waste bin to dispose of all the items after use.

The participants were instructed about when to take their meals on the test day; breakfast between 7.00 and $9.00 \mathrm{~h}$, the first snack between 10.00 and $11.00 \mathrm{~h}$, lunch between 12.00 and $14.00 \mathrm{~h}$, the second snack between 16.00 and $17.00 \mathrm{~h}$ and dinner between 18.00 and $20.00 \mathrm{~h}$. They were told not to consume any food or drink which was not provided, apart from water and hot drinks such as tea, coffee or herbal tea. They were asked to record all drinks consumed.

On the three test days: participants randomly consumed either control or flaxseed muffins in one of the following orders: (1) Flaxseed once a day: three ground flaxseed muffins with breakfast, one control muffin with lunch and dinner; (2) Flaxseed 3 times a day: one ground flaxseed muffin and two control muffins at breakfast and one flaxseed muffin at lunch and dinner; (3) Control muffins three times a day: three control muffins at breakfast and one control muffin at lunch and dinner.

On the follow-up sessions the participants attended the Oxford Brookes Centre for Nutrition and Health in the morning between 7.00 and $9.00 \mathrm{~h}$ after an overnight fast for the CGMS sensor removal. One final capillary finger-prick glucose reading was taken to calibrate the sensors before removing. There was a washout of at least 1 week between the test days. The wash out period was needed to minimise the carry over effect between the different treatments and was based on previous similar studies [19, 20].

\section{Continuous glucose monitoring system sensor}

Measurement of the 24-h glucose response was made using the Medtronic MiniMed iPro ${ }^{\circledR} 2$ Professional Continuous Glucose Monitoring (Northridge, CA, USA) which recorded glucose levels every $5 \mathrm{~min}$, giving a total of 288 readings over $24 \mathrm{~h}$. The CGMS is a technology that has been previously used in other studies [21,22]. This technology provides a full view of the glycaemic level every $5 \mathrm{~min}$, to potentially show when and to what extent, an intervention affects the glycaemic response. It also allows the participants to continue their daily lives and activities uninterrupted [21, 23, 24]. O'Riordan et al. [25] found that the CGMS performance on two occasions over a 12-month period were reliable, reproducible and repeatable.

Using an applicator or self-insertion device, a thin plastic sensor is inserted just under the skin of the abdomen by trained personnel. The receiver can store information for later use and long-term data can be downloaded to a computer programme CareLink iPro Software, which is a Web-based system, designed to generate reports and store data $[26,27]$.

\section{Muffins}

The muffins (flaxseed and control) were prepared following a standard recipe and the flaxseed muffins were prepared by replacing $48 \%$ of the flour in the control muffins with ground flaxseed each flaxseed muffins contain $10 \mathrm{~g}$ ground flaxseed. A $150 \mathrm{~g}$ sample of each muffin type was analysed for nutritional content by Eurofins Scientific Food Testing Ltd. (Wolverhampton, UK) (Table 1). To prepare the muffins, first the dry ingredients (flour, sugar, baking soda, baking powder, nutmeg and cinnamon) were sifted and thoroughly mixed together with ground flaxseed if required. The banana was mashed and the liquid ingredients (semi-skimmed milk, butter, vanilla and eggs) were mixed in before adding to the dry ingredients. All muffin mixtures were placed into nonstick petite muffin cups tray and baked at $190{ }^{\circ} \mathrm{C}\left(375^{\circ} \mathrm{F}\right)$ in a pre-heated oven for $20 \mathrm{~min}$. After baking, the muffins were allowed to cool for $10 \mathrm{~min}$ before they were then removed from the tray. Then they removed from the tray for complete cooling on a wire rack for $30 \mathrm{~min}$.

\section{Dietary intervention}

The participants were provided with pre-packaged meals for the evening meal before the test day and all meals for the test days. The meals were designed to meet the dietary reference values for energy and macronutrients for males and females based on the recommendations of the Scientific Advisory Committee on Nutrition [28]. The meals and snacks were made up from control or flaxseed muffins, orange juice, Greek style yoghurt, apple, hummus sandwich, green salad, vegetable lasagne, low fat berry medley yoghurt, nuts, orange, grapes and an oat and honey bar. Each food was labelled with the time that it should be consumed, as well as the meal type.

All meals were planned using Nutritics software ver 5.022 (Nutritics LTD, Dublin, Ireland) based on for a healthy standard adult males and females; if the meal components were not on the Nutritics database, all the energy and macronutrient information which was needed to plan the meals for 
Table 1 Muffin formulation for twelve muffins and nutrient profile per $100 \mathrm{~g}$

\begin{tabular}{|c|c|c|c|c|c|}
\hline \multirow[t]{2}{*}{ Ingredients } & \multicolumn{5}{|c|}{ Muffin formulation } \\
\hline & Unit & & Control & & Flaxseed \\
\hline Melted butter & $\mathrm{g}$ & & 75 & & 75 \\
\hline Self-rising flour & $\mathrm{g}$ & & 250 & & 130 \\
\hline Flaxseed & g & & - & & 120 \\
\hline Baking powder & $\mathrm{g}$ & & 5 & & 5 \\
\hline Bicarbonate of soda & $\mathrm{g}$ & & 2.5 & & 2.5 \\
\hline Ground cinnamon & $\mathrm{g}$ & & 2.5 & & 2.5 \\
\hline Nutmeg & $\mathrm{g}$ & & 2.5 & & 2.5 \\
\hline Caster sugar & g & & 115 & & 115 \\
\hline Vanilla extract & $\mathrm{ml}$ & & 5 & & 5 \\
\hline Large ripe bananas & $\mathrm{g}$ & & 240 & & 240 \\
\hline Medium eggs & $\mathrm{g}$ & & 106 & & 106 \\
\hline Semi skimmed milk & $\mathrm{ml}$ & & 125 & & 125 \\
\hline \multirow[t]{2}{*}{ Ingredients } & & \multicolumn{4}{|c|}{ Nutrient profile/100 g } \\
\hline & & \multicolumn{2}{|l|}{ Control } & \multicolumn{2}{|c|}{ Ground flaxseed } \\
\hline Crude protein (g) & & \multicolumn{2}{|l|}{5.5} & \multicolumn{2}{|l|}{7.2} \\
\hline Carbohydrate (avail) (g) & & \multicolumn{2}{|l|}{40.9} & \multicolumn{2}{|l|}{30.8} \\
\hline Total sugars $(\mathrm{g})$ & & \multicolumn{2}{|l|}{18.7} & \multicolumn{2}{|l|}{18.2} \\
\hline Total fat $(\mathrm{g})$ & & \multicolumn{2}{|l|}{8.5} & \multicolumn{2}{|l|}{14.9} \\
\hline Total fibre (AOAC) (g) & & \multicolumn{2}{|l|}{1.6} & \multicolumn{2}{|l|}{4.9} \\
\hline Energy (kcal) & & \multicolumn{2}{|l|}{265} & \multicolumn{2}{|l|}{296} \\
\hline Energy $(\mathrm{kJ})$ & & \multicolumn{2}{|l|}{1120} & \multicolumn{2}{|l|}{1240} \\
\hline Saturated fatty acids (g) & & \multicolumn{2}{|l|}{4.8} & \multicolumn{2}{|l|}{6.9} \\
\hline
\end{tabular}

each test day was inserted manually according to the nutrition facts label on that product.

\section{Analysis of continuous glucose monitoring system data}

All data from the sensors were downloaded to the CareLink iPro Software (MiniMed, Fridley, Minnesota) for each participant, which was coded with the participant's number and the test number; all capillary results for blood glucose levels were inserted manually for each test treatment. All the times that the meals were consumed were inserted manually and all the data were then exported to Microsoft Excel (Windows version 2010) to complete the data analysis. One day (24-h data with 288 glucose readings) was determined to be from $06: 00$ on day 1 to $06: 00$ on day 2 . For each test day, the following measurements were performed: Mean blood glucose concentration for $24 \mathrm{~h}$, day $(06.00-22.00 \mathrm{~h})$, night (22.00-06.00 h) and pre-post each main meal was recorded. The blood glucose iAUC was also calculated geometrically for each participant's blood glucose response with the $06.00 \mathrm{~h}$ glucose result used as the baseline. Blood glucose peak values for each main meal, as well as the time to peak were also recorded. The standard deviation calculated for all above measurements, except for mean blood glucose concentration over $24 \mathrm{~h}$, day and night, where standard error was calculated.

\section{Gastrointestinal symptoms}

A gastrointestinal symptoms questionnaire was provided to be filled in after each meal for $24 \mathrm{~h}$ after each test day. The questionnaire was used to assess four different gastrointestinal symptoms nausea, abdominal cramping, distension and flatulence. Participants rated the frequency and the severity of those symptoms. The scales were used to assess frequency (100 $\mathrm{mm}=$ 'much more often than normal' to $0 \mathrm{~mm}=$ 'not more often than normal') and severity (100 mm = "very severe' to $0 \mathrm{~mm}=$ 'none') of the symptoms [26].

\section{Statistical analysis}

The required sample size for this study was estimated to be 15 to be able to detect a 5\% difference between 3 days in the overall blood glucose iAUC with the confidence level as $95 \%$ and for a medium effect size, with $\alpha-0.05$ (two-tailed) using $\mathrm{G}^{*}$ power (Version 3.0.10). The power of study was 
$90 \%$ and the number of participants was based on the previous studies [29, 30].

Statistical analysis was performed using SPSS software, (Statistical Package for the Social Sciences) version 25, (Chicago, USA). Prior to statistical analysis, the normality of the data was assured using the Shapiro-Wilks statistical test to investigate the normality of the data; where data were not normally distributed, non-parametric tests were used.

All results were reported as the mean \pm SD or SEM (not normally distributed data). Differences in mean blood glucose concentration, time to peak, iAUC and gastrointestinal symptoms between the three test days were assessed using repeated measures ANOVA followed by Bonferroni correction for multiple comparisons if the data were parametric, or the Friedman test and Wilcoxon tests for non-parametric data. $p<0.05$ was considered statistically significant.

The Pearson correlation coefficient and the method Bland-Altman technique [31] were used to assess the correlation and agreement between the CGMS sensor data and ACCU-CHEK ${ }^{\circledR}$ data.

\section{Results}

\section{Participants characteristics}

Fifteen healthy adults (ten female, five male) were recruited (Table 2).

\section{Comparison of continuous glucose monitoring system and the capillary blood glucose readings}

The results showed there was a strong correlation observed between the CGMS and the capillary blood finger-pricks carried out using Accu-Chek for the 405 paired glucose readings $(r=0.57, p<0.001)$.

The Bland-Altman analysis indicated a good agreement between the CGMS and Accu-Chek for glucose level for 405 paired readings (mean difference $0.1 \mathrm{mmol}$; $95 \%$ confidence interval -0.166 to -0.034 ; limits of agreement -1.4

Table 2 Baseline characteristics of fifteen participants (mean \pm SD)

\begin{tabular}{lccc}
\hline & All $(n=15)$ & Male $(n=5)$ & Female $(n=10)$ \\
\hline Age $(\mathrm{y})$ & $30.3 \pm 9.1$ & $25.0 \pm 3.8$ & $32.9 \pm 10.0$ \\
Height $(\mathrm{m})$ & $1.7 \pm 0.1$ & $1.8 \pm 0.1$ & $1.6 \pm 0.8$ \\
Weight $(\mathrm{kg})$ & $69.7 \pm 13.3$ & $81.4 \pm 8.4$ & $63.8 \pm 11.8$ \\
BMI $\left(\mathrm{kg} / \mathrm{m}^{2}\right)$ & $24.1 \pm 2.9$ & $24.6 \pm 2.8$ & $23.8 \pm 3.1$ \\
Body fat\% & $25 \pm 9.3$ & $18.2 \pm 5$ & $29.4 \pm 8.9$ \\
$\begin{array}{l}\text { Fasting blood glu- } \\
\text { cose }(\mathrm{mmol} / \mathrm{l})\end{array}$ & $5.0 \pm 0.3$ & $5.0 \pm 0.5$ & $5.0 \pm 0.3$ \\
\hline
\end{tabular}

to $1.3 \mathrm{mmol})$. These results suggest that the data from the CGMS is reliable (Fig. 1).

\section{Blood glucose profile}

The blood glucose profile over $24 \mathrm{~h}$ for control muffins, once-a-day flaxseed muffins and three-times-a-day flaxseed muffins is presented in (Fig. 2). All the investigations showed the same trend: splitting the portion of flaxseed to three times a day produced the lowest results, followed by flaxseed muffins once a day, while the control muffins had the highest glucose levels.

\section{Blood glucose iAUC}

The blood glucose iAUC results (Table 3) show that adding flaxseed muffins to the diet whether in one portion or split
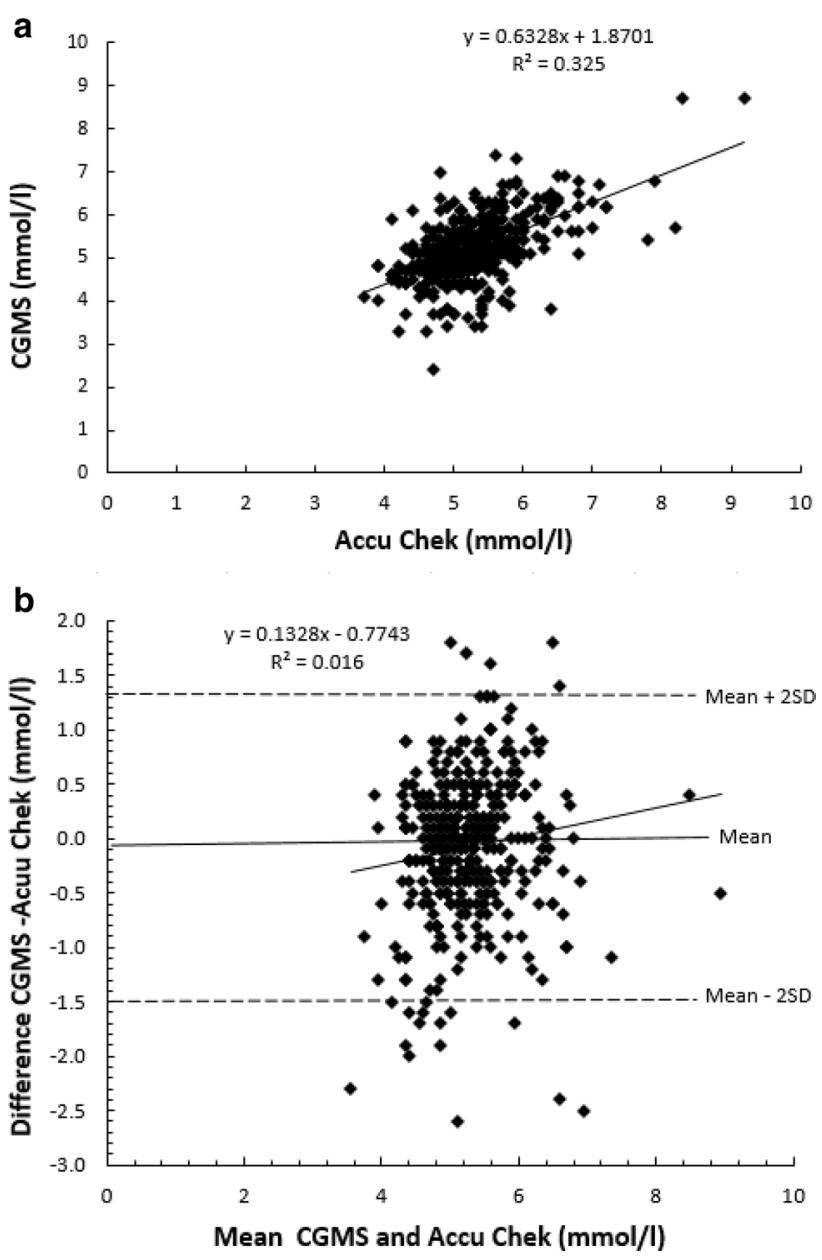

Fig. 1 a Pearson regression of 405 paired glucose measurements between the Continuous Glucose Monitoring Systems (CGMS) and finger-prick blood glucose monitoring device (Accu-Chek) data. b Bland-Altman analysis of 405 paired glucose measurements between the CGMS and Accu-Chek data 
over three times a day, had the effect of lowering the blood glucose iAUC over $24 \mathrm{~h}$, this was significant between the control muffins and flaxseed three times a day $(p=0.014)$. During the night there were significant differences between the control muffins and both flaxseed treatments (flaxseed once a day and flaxseed three times a day) $(p=0.005)$. There was no significant difference between the flaxseed treatments.

\section{Absolute blood glucose level}

The results for the absolute blood glucose level for each test day (control muffins, flaxseed muffin once per day and flaxseed muffins three times per day) over $24 \mathrm{~h}$, over the daytime and over the night-time are shown in (Table 4). There were no significant differences in absolute blood glucose between the test days for any examined time period, except for the night (22.00-6.00 h) where there was a significant reduction $(p=0.011)$ in blood glucose concentration after consuming flaxseed once $(4.8 \pm 0.3 \mathrm{mmol} / \mathrm{l})$ compared to the control muffins $(5.2 \pm 0.1 \mathrm{mmol} / \mathrm{l})$.
Fig. 2 Mean change in blood glucose (mmol/l) during $24 \mathrm{~h}$, for each test day $(n=15)$

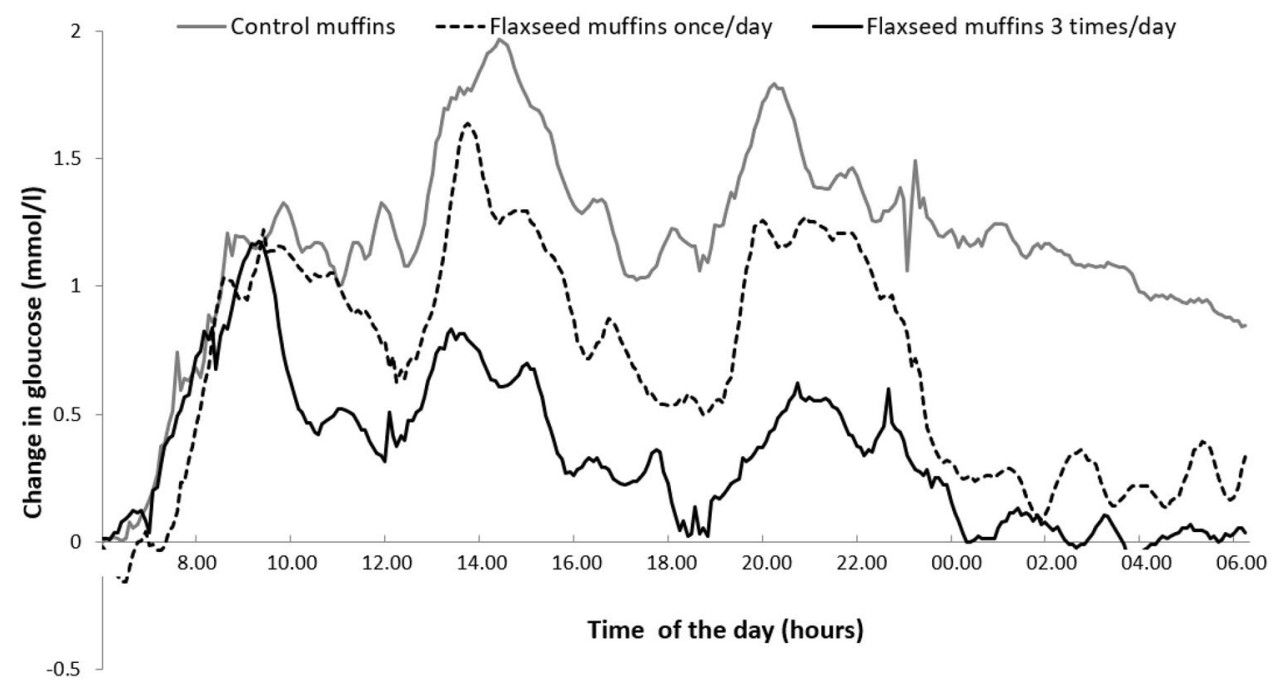

Table 3 Blood glucose iAUC for all (24 h) and sections (daytime, morning, afternoon and evening, night-time) of each test day (mean \pm SD)

\begin{tabular}{|c|c|c|c|c|}
\hline & Control muffins (mmol/l) & $\begin{array}{l}\text { Flaxseed muffins } \\
\text { once/day }(\mathrm{mmol} / \mathrm{l})\end{array}$ & $\begin{array}{l}\text { Flaxseed muffins } 3 \\
\text { times/day }(\mathrm{mmol} / \mathrm{l})\end{array}$ & $P$ values \\
\hline $24 \mathrm{~h}$ iAUC $(6.00-6.00 \mathrm{~h})$ & $1760.1 \pm 1087.7$ & $1214 \pm 1065.4$ & $893.8 \pm 692.8^{\mathrm{a}}$ & 0.014 \\
\hline Daytime iAUC (6.00-22.00 h) & $1207.0 \pm 728.2$ & $931.7 \pm 787.6$ & $689.6 \pm 448.4$ & 0.127 \\
\hline Morning iAUC Day $(6.00-12.00 \mathrm{~h})$ & $312.8 \pm 183.9$ & $287.4 \pm 245.0$ & $224.4 \pm 139.8$ & 0.627 \\
\hline Afternoon-evening iAUC Day $(12.00-22.00 \mathrm{~h})$ & $768.8 \pm 478.3$ & $648.9 \pm 564.2$ & $470.3 \pm 352.8$ & 0.057 \\
\hline Night-time iAUC (22.00-6.00 h) & $553.1 \pm 382.3$ & $282.3 \pm 292.4^{\mathrm{a}}$ & $204.2 \pm 276.5^{\mathrm{a}}$ & 0.005 \\
\hline
\end{tabular}

${ }^{\text {a }}$ Significant difference $(p<0.05)$ compared to control muffins

Table 4 Average blood glucose concentration $(\mathrm{mmol} / \mathrm{l})$ for all (24 h) and sections (daytime, morning, afternoon and evening, night-time) of each test day $($ mean \pm SEM)

\begin{tabular}{lllll}
\hline & $\begin{array}{l}\text { Control muf- } \\
\text { fins (mmol/l) }\end{array}$ & $\begin{array}{l}\text { Flaxseed muffins } \\
\text { once/day }(\mathrm{mmol} / \mathrm{l})\end{array}$ & $\begin{array}{l}\text { Flaxseed muffins 3 } \\
\text { times/day (mmol/l) }\end{array}$ & $P$ values \\
\hline $24 \mathrm{~h}(6.00-6.00 \mathrm{~h})$ & $5.2 \pm 0.1$ & $5.1 \pm 0.1$ & $5.2 \pm 0.1$ & 0.419 \\
Day time $(6.00-22.00 \mathrm{~h})$ & $5.2 \pm 0.1$ & $5.3 \pm 0.1$ & $5.4 \pm 0.1$ & 0.436 \\
Morning $(6.00-12.00 \mathrm{~h})$ & $4.9 \pm 0.2$ & $5.0 \pm 0.2$ & $5.3 \pm 0.1$ & 0.175 \\
Afternoon-evening $(12.00-22.00 \mathrm{~h})$ & $5.5 \pm 0.1$ & $5.4 \pm 0.1$ & $5.4 \pm 0.1$ & 0.745 \\
Night-time $(22.00-6.00 \mathrm{~h})$ & $5.2 \pm 0.1$ & $4.8 \pm 0.3^{\mathrm{a}}$ & $5.0 \pm 0.1$ & 0.011 \\
\hline
\end{tabular}

${ }^{a}$ Significant difference $(p<0.05)$ compared to control muffins 


\section{Blood glucose peak values and time to peak}

The peak and time to peak of each of the three meals consumed during the day (Table 5) were not significantly different between the test days.

\section{Gastrointestinal symptoms}

The effect of adding flaxseed to muffins on gastrointestinal symptoms $24 \mathrm{~h}$ post consumption was investigated and the results (Fig. 3) for the frequency and intensity for all the symptoms were similar for both flaxseed treatments. There was significant differences between both flaxseed treatments and the control muffins $(p<0.001)$ for the frequency and intensity of abdominal cramping and frequency of flatulence.

\section{Discussion}

The present study aimed to investigate the effect of adding flaxseed to muffins in one single portion, or split into three portions consumed throughout the day, on blood glucose
Table 5 Blood glucose peak and time to peak for each main meal for each test day $($ mean $\pm \mathrm{SD})$
Fig. 3 Mean frequency (a) and intensity (b) of some gastrointestinal symptoms $24 \mathrm{~h}$ post consumption for each test day $(n=15)$. *Significant difference $(p<0.05)$ compared to control muffins

\begin{tabular}{lcccc}
\hline & Control muffins & $\begin{array}{l}\text { Flaxseed muffins } \\
\text { once/day }\end{array}$ & $\begin{array}{l}\text { Flaxseed muffins 3 } \\
\text { times/day }\end{array}$ & $P$ values \\
\hline Peak breakfast (mmol/l) & $6.4 \pm 0.8$ & $6.0 \pm 0.8$ & $6.4 \pm 1.0$ & 0.207 \\
Peak lunch (mmol/l) & $6.4 \pm 0.8$ & $6.4 \pm 1.0$ & $6.4 \pm 0.8$ & 0.920 \\
Peak dinner (mmol/l) & $6.3 \pm 0.4$ & $6.4 \pm 0.9$ & $6.1 \pm 0.7$ & 0.307 \\
Time to peak breakfast (min) & $9.52 \pm 1.5$ & $9.50 \pm 1.3$ & $9.57 \pm 1.6$ & 0.970 \\
Time to peak lunch (min) & $15.00 \pm 2.0$ & $14.37 \pm 1.7$ & $14.45 \pm 0.1$ & 0.420 \\
Time to peak dinner (min) & $18.27 \pm 6.6$ & $19.50 \pm 4.1$ & $20.00 \pm 4.7$ & 0.169 \\
\hline
\end{tabular}
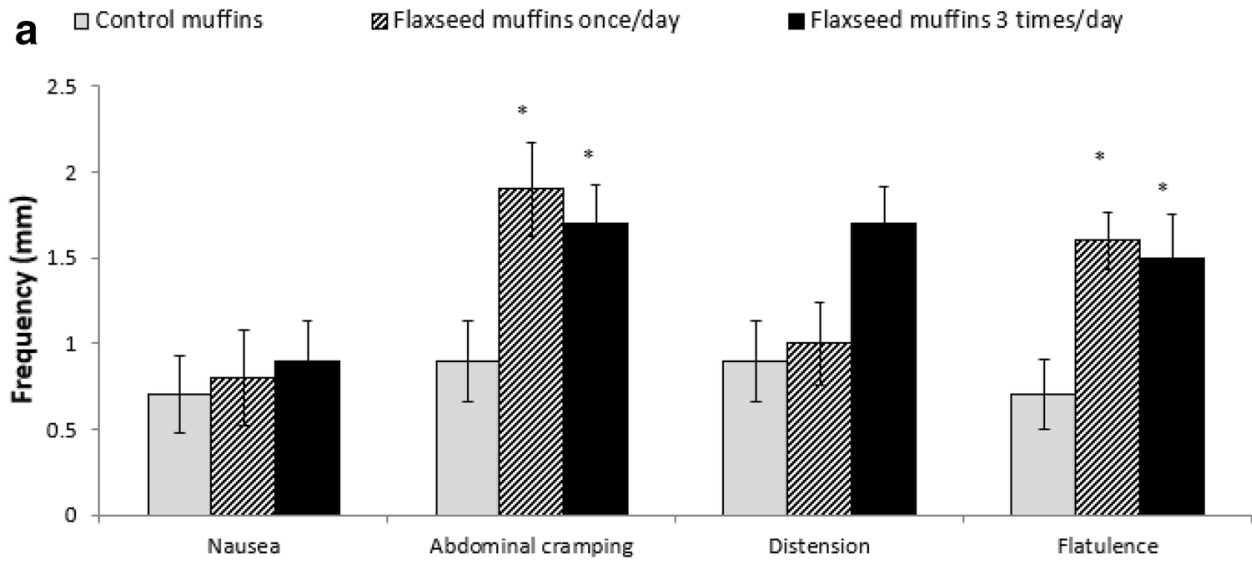

Gastrointestinal symptoms

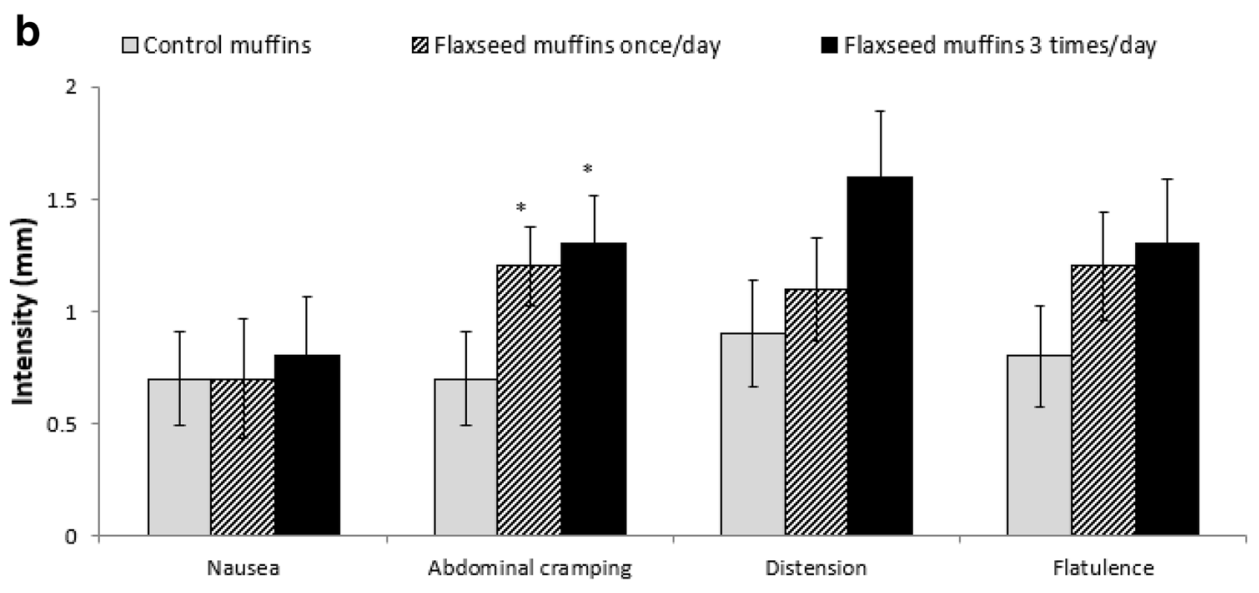

Gastrointestinal symptoms 
profile using CGMS among healthy participants. The results of this study demonstrated that flaxseed muffins given 3 times a day were effective at lowering and maintaining blood glucose levels over $24 \mathrm{~h}$, compared to the control muffins and that both flaxseed treatments resulting in a lower blood glucose iAUC during the night. To the best of our knowledge there is currently no previous study that has investigated the effect of flaxseed on blood glucose response over an entire 24-h period.

Reliable evidence has shown that the consumption of low GI food reduces large blood glucose fluctuations [2, 5]. It has been deduced from various studies that low GI foods ingested at breakfast reduce glycaemia after a subsequent standardised lunch; a phenomenon known as the "secondmeal effect". In the short and medium terms, the consumption of food which causes a second-meal effect may assist in sustaining low blood glucose concentrations, consequently reducing demands upon the insulin-mediated blood glucose regulatory systems [5]. This implies that first meal of the day (breakfast) may be the largest contributor to daily glycaemic control, which can result in improvements in glucose tolerance for subsequent meals such as lunch and dinner [32, 33] if low GI foods are consumed. A possible mechanism is that breakfast may serve as primer to the insulin-sensitive tissues either by: (1) adjusting $\beta$-cell responses with changed incretin signalling or (2) an insulin sensitivity change following breakfast [34] as several studies have demonstrated greater insulin sensitivity in the morning than there is in the afternoon [35]. Although the results of the current study did not show differences after each of the individual meals, this effect is applicable to the current study as the results of iAUC over $24 \mathrm{~h}$ was significantly lower when flaxseed muffins were consumed once a day, as well as when they were split across the day, compared to the control.

Many studies have looked at the effect of low GI foods on the blood glucose profile over $24 \mathrm{~h}$ among healthy participants [2, 19, 21, 22]. The blood glucose profile over 24-h for the above studies showed lower values following low GI food, especially during the night which is consistent with the results of the current study. The results for blood glucose iAUC during the night indicated that both flaxseed treatments produced lower readings than the control muffins. This is an important finding as much of the research to date on flaxseed has focused on the postprandial period; however, this demonstrates an improved hepatic insulin sensitivity, effectively decreasing hepatic glucose output throughout the night from just the consumption of either one single $30 \mathrm{~g}$ dose of flaxseed or three $10 \mathrm{~g}$ doses dispersed throughout the day.

Studies have shown that low GI diets in healthy adults can significantly lower fasting plasma glucose levels, which suggests that by switching to a low GI diet an improvement in hepatic insulin sensitivity that would effectively decrease the hepatic glucose output [19]. If these changes are applied over the long term they could potentially improve glucose control, which could result in a reduced chronic disease risk such T2D and CVD [21]. The impact of the reduction of blood glucose is a basic element of a low GI diet and the mechanisms underlying the metabolic impacts are multifactorial including glucose absorption, a reduced gastric emptying rate, the food matrix, a slower small-intestinal transit as well as a decreased insulin response [36].

Flaxseeds contain many components known to impact blood glucose. It is well established that soluble dietary fibre can impact blood glucose control through delayed absorption within the gastrointestinal tract $[37,38]$. The flaxseed muffins contained $4.9 \mathrm{~g} / 100 \mathrm{~g}$ of fibre, which could be one of the main reasons for the changes in blood glucose seen in the current study. However, a recent study compared the intake of flaxseed or psyllium for 12 weeks and found flaxseed to have superior impacts on glycaemic response [15] suggesting that other components may also contribute to the reduction in blood glucose. Flaxseed contains n-3 fatty acids alpha-linolenic acid has which has previously been shown to have a positive impact upon glycaemic control $[37,38]$. A previous systematic review and meta-analysis [14] showed that there was a significant association between flaxseed supplementation and a reduction in blood glucose; however, when subgroup analysis was completed the significant reduction in blood glucose were found only in studies using whole flaxseed but not flaxseed oil and lignan extract. However, the flaxseed oil was approaching significance $(p=0.08)$. Although the systematic review by MohammadiSartang et al. [14] highlighted that flaxseed lignan extract had no significant impact on blood glucose, plant lignan has been suggested to be able to lower the risk of cardiovascular diseases as well as inhibit the effect of developing type two diabetes by reducing inflammatory response and insulin resistance [39]. It has been shown that flaxseed lignan secoisolariciresinol diglucoside restricts expression of the phosphoenolpyruvate carboxykinase gene, which is considered the main enzyme in glucose synthesis in the liver [40, 41]. The richest source of plant lignans is flaxseed which incorporates approximately 75-800 times more lignans in comparison to cereal grains, legumes, fruits and vegetables [9]. Finally, the protein in the flaxseed may also cause an increased insulin secretion resulting in decreased blood glucose [42]. It is likely that the reductions in blood glucose observed in the current study are due to the cumulative effects of all of these components and their associated mechanism; however, further clinical trials are required to confirm this.

The amount of flaxseed added to the muffins in the current study was based on a study by $\mathrm{Wu}$ et al. [43], who found that $30 \mathrm{~g}$ of milled flaxseed was effective in lowering blood glucose. Lipilina and Ganji [44] also demonstrated that 
replacing $50 \%$ of the flour with ground flaxseed resulted in the most acceptable sensory evaluation compared to the control bread with wheat flour. In this study $30 \mathrm{~g}$ of flaxseed equalled a $48 \%$ replacement of flour. Ground flaxseed has also been shown to enhance the sensory attributes of muffins and could be added in high amounts (up to 50\%) without any negative effects [45]. Due to a recent report from the European Food Safety Authority (EFSA), there have been some concerns about flaxseed due to the presences of cyanogenic glycosides, with many media outlets reporting that their intake should be limited especially in infants [46]. EFSA have now clarified this misconception. They highlight that $14.7 \mathrm{~g}$ of flaxseed per day could reach the Acute Reference Dose. The Acute Reference Dose refers to an estimate of a daily oral exposure for an acute duration ( $24 \mathrm{~h}$ or less) to the human population that is likely to be without an appreciable risk of deleterious effects during a lifetime [47]. EFSA also highlight that there is overall uncertainty with the present assessment, and it is more likely to overestimate than to underestimate the risk. However, future studies should examine smaller doses and the implications this can have on 24-h glycaemic responses, particularly as flaxseeds are most often consumed with or as apart of breakfast. Furthermore, the extent of granularity of the flaxseed was not measured in the current study and little is known about how the degree of granularity effects glycaemic response and bioavailability of flaxseed nutrients.

The current study also investigated gastrointestinal symptoms compared with the control muffins and found that flaxseed muffins of both treatment regimens caused some side effects on the gastrointestinal system. This is consistent with the results of Kristensen et al. [48], who found that $5 \mathrm{~g}$ flaxseed dietary fibre supplementation for 12 weeks (with or without the addition of calcium) resulted in some gastrointestinal symptoms, especially abdominal pain, flatus and diarrhoea, which may be due to the amount of dietary fibre in the flaxseed. These results suggest flaxseed muffins can cause some gastrointestinal side effects, although they were not severe as the highest mean value was only 1.9 on a scale of $1-10$.

\section{Conclusions}

The results of this study indicated that adding flaxseed to the diet can produce a lower glucose profile over $24 \mathrm{~h}$ in a freeliving context compared to the control muffins. Furthermore, flaxseeds were effective in improving the blood glucose profile over the $24 \mathrm{~h}$; however, to improve blood glucose both over $24 \mathrm{~h}$ and overnight flaxseeds are better consumed in smaller amounts dispersed throughout the day. This study provides important data about adding flaxseed to the diet for healthy individuals, which can improve glycaemic response throughout the day and overnight.

Acknowledgements Authors would like to acknowledge the participants in this study. Thanks to the Oxford Brookes University, the home institution of this project.

Author contributions MEC, HL, MC and AA conceptualised the study and designed the methodology. AA undertook the data collection. MEC, HL, MC and AA were involved in formal analysis of the data. MEC and AA drafted the manuscript and all authors approved the final version.

Funding This research was funded by the Ministry of High education of Saudi Arabia and Umm Al-Qura University.

\section{Compliance with ethical standards}

Conflict of interest The authors declare no conflict of interest.

Open Access This article is licensed under a Creative Commons Attribution 4.0 International License, which permits use, sharing, adaptation, distribution and reproduction in any medium or format, as long as you give appropriate credit to the original author(s) and the source, provide a link to the Creative Commons licence, and indicate if changes were made. The images or other third party material in this article are included in the article's Creative Commons licence, unless indicated otherwise in a credit line to the material. If material is not included in the article's Creative Commons licence and your intended use is not permitted by statutory regulation or exceeds the permitted use, you will need to obtain permission directly from the copyright holder. To view a copy of this licence, visit http://creativecommons.org/licenses/by/4.0/.

\section{References}

1. Riccardi G, Rivellese AA, Giacco R (2008) Role of glycemic index and glycemic load in the healthy state, in prediabetes, and in diabetes. Am J Clin Nutr 87(1):269S-274S

2. Brand-Miller J, Hayne S, Petocz P, Colagiuri S (2003) Low-glycemic index diets in the management of diabetes: a meta-analysis of randomized controlled trials. Diabetes Care 26(8):2261-2267

3. Brand-Miller JC, Holt SH, Pawlak DB, McMillan J (2002) Glycemic index and obesity. Am J Clin Nutr 76(1):281S-S285

4. Willett W, Manson J, Liu S (2002) Glycemic index, glycemic load, and risk of type 2 diabetes. Am J Clin Nutr 76(1):274S-S280

5. Kaur B, Chin QY (2016) The impact of a low glycaemic index (GI) diet on simultaneous measurements of blood glucose and fat oxidation: a whole body calorimetric study. J Clin Transl Endocrinol 4:45-52

6. DECODE Study Group (1999) European Glucose tolerance and mortality: comparison of WHO and American Diabetes Association diagnostic criteria Diabetes Epidemiology Group Diabetes Epidemiology: Collaborative analysis Of Diagnostic criteria in Europe. Lancet 354(9179):617-621

7. Beisswenger P, Heine RJ, Leiter LA, Moses A, Tuomilehto J (2004) Prandial glucose regulation in the glucose triad: emerging evidence and insights. Endocrine 25(3):195-202

8. de Vegt F, Dekker JM, Ruhe HG, Stehouwer CD, Nijpels G, Bouter LM, Heine RJ (1999) Hyperglycaemia is associated with all-cause and cardiovascular mortality in the Hoorn population: the Hoorn Study. Diabetologia 42(8):926-931 
9. Singh KK, Mridula D, Rehal J, Barnwal P (2011) Flaxseed: a potential source of food, feed and fiber. Crit Rev Food Sci Nutr 51(3):210-222

10. Goyal A, Sharma V, Upadhyay N, Gill S, Sihag M (2014) Flax and flaxseed oil: an ancient medicine and modern functional food. $\mathrm{J}$ Food Sci Technol 51(9):1633-1653

11. Cunnane SC, Hamadeh MJ, Liede AC, Thompson LU, Wolever TM, Jenkins DJ (1995) Nutritional attributes of traditional flaxseed in healthy young adults. Am J Clin Nutr 61(1):62-68

12. Thakur G, Mitra A, Pal K, Rousseau D (2009) Effect of flaxseed gum on reduction of blood glucose and cholesterol in type 2 diabetic patients. Int J Food Sci Nutr 60(Suppl 6):126-136

13. Hutchins AM, Brown BD, Cunnane SC, Domitrovich SG, Adams ER, Bobowiec CE (2013) Daily flaxseed consumption improves glycemic control in obese men and women with prediabetes: a randomized study. Nutr Res 33(5):367-375

14. Mohammadi-Sartang M, Sohrabi Z, Barati-Boldaji R, RaeisiDehkordi H, Mazloom Z (2018) Flaxseed supplementation on glucose control and insulin sensitivity: a systematic review and meta-analysis of 25 randomized, placebo-controlled trials. Nutr Rev 76(2): 125-139

15. Soltanian N, Janghorbani M (2019) Effect of flaxseed or psyllium vs. placebo on management of constipation, weight, glycemia, and lipids: a randomized trial in constipated patients with type 2 diabetes. Clin Nutr ESPEN 29:41-48

16. Mastrototaro J (1999) The MiniMed continuous glucose monitoring system (CGMS). J Pediatr Endocrinol Metab 12(3):751-758

17. Phillip M, Danne T, Shalitin S, Buckingham B, Laffel L, Tamborlane W, Battelino T, Consensus Forum P (2012) Use of continuous glucose monitoring in children and adolescents $(*)$. Pediatr Diabetes 13(3):215-228

18. Camps SG, Kaur B, Quek RYC, Henry CJ (2017) Does the ingestion of a 24 hour low glycaemic index Asian mixed meal diet improve glycaemic response and promote fat oxidation? A controlled, randomized cross-over study. Nutr J 16(1):43

19. Brynes AE, Adamson J, Dornhorst A, Frost GS (2005) The beneficial effect of a diet with low glycaemic index on $24 \mathrm{~h}$ glucose profiles in healthy young people as assessed by continuous glucose monitoring. Br J Nutr 93(2): 179-182

20. Morgan LM, Shi JW, Hampton SM, Frost G (2012) Effect of meal timing and glycaemic index on glucose control and insulin secretion in healthy volunteers. Br J Nutr 108(7):1286-1291

21. Henry CJ, Lightowler HJ, Tydeman EA, Skeath R (2006) Use of low-glycaemic index bread to reduce 24-h blood glucose: implications for dietary advice to non-diabetic and diabetic subjects. Int J Food Sci Nutr 57(3):273-278

22. Henry CJ, Newens KJ, Lightowler HJ (2009) Low-glycaemic index sweetener-based beverages reduce 24 -h glucose profiles in healthy adults. J Hum Nutr Diet 22(1):77-80

23. Chico A, Vidal-Rios P, Subira M, Novials A (2003) The continuous glucose monitoring system is useful for detecting unrecognized hypoglycemias in patients with type 1 and type 2 diabetes but is not better than frequent capillary glucose measurements for improving metabolic control. Diabetes Care 26(4):1153-1157

24. Wilson DM, Beck RW, Tamborlane WV, Dontchev MJ, Kollman C, Chase P, Fox LA, Ruedy KJ, Tsalikian E, Weinzimer SA (2007) DirecNet Study G 2007 The accuracy of the FreeStyle Navigator continuous glucose monitoring system in children with type 1 diabetes. Diabetes Care 30(1):59-64

25. O'Riordan SM, Hindmarsh P, Hill NR, Matthews DR, George S, Greally P, Canny G, Slattery D, Murphy N, Roche E, Costigan C, Hoey $\mathrm{H}$ (2009) Validation of continuous glucose monitoring in children and adolescents with cystic fibrosis: a prospective cohort study. Diabetes Care 32(6):1020-1022
26. Kaufman FR, Gibson LC, Halvorson M, Carpenter S, Fisher LK, Pitukcheewanont P (2001) A pilot study of the continuous glucose monitoring system: clinical decisions and glycemic control after its use in pediatric type 1 diabetic subjects. Diabetes Care 24(12):2030-2034

27. Hanaire $\mathrm{H}$ (2006) Continuous glucose monitoring and external insulin pump: towards a subcutaneous closed loop. Diabetes Metab 32(5):534-538

28. Scientific Advisory Committee on Nutrition (2012) Dietary reference values for energy. TSO, London, UK

29. Imai S, Kajiyama S, Hashimoto Y, Yamane C, Miyawaki T, Ozasa N, Tanaka M, Fukui M (2017) Divided consumption of late-nightdinner improves glycemic excursions in patients with type 2 diabetes: a randomized cross-over clinical trial. Diabetes Res Clin Pract 129:206-212

30. Kajiyama S, Imai S, Hashimoto Y, Yamane C, Miyawaki T, Matsumoto S, Ozasa N, Tanaka M, Kajiyama S, Fukui M (2018) Divided consumption of late-night-dinner improves glucose excursions in young healthy women: a randomized cross-over clinical trial. Diabetes Res Clin Pract 136:78-84

31. Bland JM, Altman DG (1986) Statistical methods for assessing agreement between two methods of clinical measurement. Lancet 1(8476):307-310

32. Nilsson AC, Ostman EM, Granfeldt Y, Bjorck IM (2008) Effect of cereal test breakfasts differing in glycemic index and content of indigestible carbohydrates on daylong glucose tolerance in healthy subjects. Am J Clin Nutr 87(3):645-654

33. Fletcher EA, Salmon J, McNaughton SA, Orellana L, Wadley GD, Bruce C, Dempsey PC, Lacy KE, Dunstan DW (2018) Effects of breaking up sitting on adolescents' postprandial glucose after consuming meals varying in energy: a cross-over randomised trial. J Sci Med Sport 21(3):280-285

34. Park YM, Heden TD, Liu Y, Nyhoff LM, Thyfault JP, Leidy HJ, Kanaley JA (2015) A high-protein breakfast induces greater insulin and glucose-dependent insulinotropic peptide responses to a subsequent lunch meal in individuals with type 2 diabetes. J Nutr 145(3):452-458

35. Shih KC, Ho LT, Kou HF, Liu PC, Hsiao LC, Li SH, Liu YF, Wu MS (1992) Diurnal variation of insulin sensitivity in NIDDM patients and normal subjects. J Formos Med Assoc 91(3):263-269

36. Wolever TM (1990) Relationship between dietary fiber content and composition in foods and the glycemic index. Am J Clin Nutr 51(1):72-75

37. Hallund J, Tetens I, Bugel S, Tholstrup T, Bruun JM (2008) The effect of a lignan complex isolated from flaxseed on inflammation markers in healthy postmenopausal women. Nutr Metab Cardiovasc Dis 18(7):497-502

38. Au MM, Goff HD, Kisch JA, Coulson A, Wright AJ (2013) Effects of soy-soluble fiber and flaxseed gum on the glycemic and insulinemic responses to glucose solutions and dairy products in healthy adult males. J Am Coll Nutr 32(2):98-110

39. Mueller K, Eisner P, Yoshie-Stark Y, Nakada R, Kirchhoff E (2010) Functional properties and chemical composition of fractionated brown and yellow linseed meal. J Food Eng 98(4):453-460

40. Pan A, Sun J, Chen Y, Ye X, Li H, Yu Z, Wang Y, Gu W, Zhang X, Chen X, Demark-Wahnefried W, Liu Y, Lin X (2007) Effects of a flaxseed-derived lignan supplement in type 2 diabetic patients: a randomized, double-blind, cross-over trial. PLoS ONE 2(11):e1148

41. Prasad K (2002) Suppression of phosphoenolpyruvate carboxykinase gene expression by secoisolariciresinol diglucoside (SDG), a new antidiabetic agent. Int J Angiol 11(2):107-109

42. Nuttall FQ, Mooradian AD, Gannon MC, Billington C, Krezowski $P$ (1984) Effect of protein ingestion on the glucose and 
insulin response to a standardized oral glucose load. Diabetes Care 7(5):465-470

43. Wu H, Pan A, Yu Z, Qi Q, Lu L, Zhang G, Yu D, Zong G, Zhou Y, Chen X, Tang L, Feng Y, Zhou H, Chen X, Li H, DemarkWahnefried W, Hu FB, Lin X (2010) Lifestyle counseling and supplementation with flaxseed or walnuts influence the management of metabolic syndrome. J Nutr 140(11):1937-1942

44. Lipilina E, Ganji V (2009) Incorporation of ground flaxseed into bakery products and its effect on sensory and nutritional characteristics - a pilot study. J Foodservice 20(1):52-59

45. Alpers L, Sawyer-Morse MK (1996) Eating quality of banana nut muffins and oatmeal cookies made with ground flaxseed. J Am Diet Assoc 96(8):794-796
46. Adams S (2019) Scientists warn too much of 'superfood' porridge topping flaxseed 'could cause cyanide poisoning in Daily Mail. Superfood 2:19

47. EFSA Panel on Contaminents in the Food Chain (CONTAM) (2019) Evaluation of the health risks related to the presence of cyanogenic glycosides in foods other than raw apricot kernels. EFSA J 17(4):5662

48. Kristensen M, Juul SR, Sørensen KV, Lorenzen JK, Astrup A (2017) Supplementation with dairy calcium and/or flaxseed fibers in conjunction with orlistat augments fecal fat excretion without altering ratings of gastrointestinal comfort. Nutr Metab 14(1):21-23 